\title{
Impacto da educação cívica sobre o conhecimento político: a experiência do programa Parlamento Jovem de Minas Gerais
}

\begin{tabular}{c}
\hline Thiago Sampaio \\
Doutorando em Ciência Política \\
Universidade Federal de Minas Gerais \\
Marina Siqueira \\
Mestranda em Ciência Política \\
Universidade Federal de Minas Gerais \\
\hline \hline
\end{tabular}

\begin{abstract}
Resumo: Nas últimas três décadas, programas de educação cívica tornaram-se recorrentes em várias partes do mundo. Tais programas possuem como princípio formulador o compromisso de imbuir nos envolvidos valores democráticos, desmistificar o mundo da política e fomentar o interesse sobre a atuação do Legislativo. Este artigo analisa o processo cognitivo de aprendizagem dos participantes do principal programa de educação cívica desenvolvido em Minas Gerais, o Parlamento Jovem (PJ), e também discorre sobre os motivos que levam programas de educação cívica como o PJ a obterem resultados opostos aos esperados. Além disso, apresenta os meandros da construção do conhecimento político nos participantes e o impacto do PJ. A análise parte de dados obtidos na pesquisa quase-experimental “O Parlamento Jovem como espaço de socialização política?".
\end{abstract}

Palavras-chaves: Parlamento Jovem; educação cívica; engajamento cívico; afeto; cognição política

\begin{abstract}
In the last three decades, civic education programs have become recurring in many parts of the world. Such programs have as principle formulator the commitment to instill democratic values, demystify the world of politics and foster interest in the work of the legislative. This article examines the cognitive process of learning of the participants of the main civic education program developed in Minas Gerais, the Parlamento Jovem (PJ). As also discusses the reasons why civic education programs such as the PJ to obtain opposite results than expected. Moreover, this paper presents the intricacies of the construction of political knowledge among the participants and the impact of the PJ. The analysis is based on data obtained in the quasiexperimental study "The young Parliament as locus of political socilaization?".
\end{abstract}

Keywords: The Young Parliament; civic education; civic engagement; affect; policy cognition 
SAMPAIO, T.; SIQUEIRA, M. Impacto da educação cívica sobre o conhecimento político...

\section{Introdução ${ }^{1}$}

O presente artigo analisa os efeitos gerados por programas de educação cívica na formação de jovens cidadãos e verifica os fatores que levam à disparidade de conhecimento político entre os atores envolvidos em tais programas. Nos últimos anos, programas de educação cívica foram fomentados com o intuito de disseminar valores democráticos, sobretudo entre os jovens de países com instituições políticas frágeis e instáveis.

Nesse sentido, espera-se que, a partir de intervenções focadas na informação e na vivência de situações políticas, seja possível ampliar o conhecimento e interesse pelas questões políticas, como também reordenar atitudes e valores possibilitando ações pautadas por princípios democráticos (FINKEL \& SMITH, 2011). No entanto, quais são os verdadeiros benefícios de tais programas para a construção de uma sociedade mais democrática? De fato, quais são as variáveis que impactam a aquisição de conhecimento político dos jovens?

Para responder a essas indagações, este artigo analisa o caso do Projeto Parlamento Jovem (PJ) de Minas Gerais, edição de 2008. O PJ é exemplar na compreensão de como se estruturam os programas de educação cívica no Brasil, pois ele agrega as características que regem o funcionamento e objetivos dos vários outros programas em execução.

O PJ tem como público alvo os jovens do ensino médio das escolas públicas e privadas de Belo Horizonte (MG). O programa nasceu da parceria entre a Escola do Legislativo de Minas Gerais (ELMG) . vinculada à Assembleia Legislativa do Estado de Minas Gerais (ALMG) - e a Pontifícia Universidade Católica de Minas Gerais (PUC Minas).

No Brasil, os programas de educação cívica possuem como característica marcante serem promovidos pelo Poder Legislativo ${ }^{2}$ em articulação com ONGs, escolas e agentes internacionais. Tais programas, em sua maioria, são gestados com objetivos que vão além do simples fortalecimento da democracia: por trás, há, geralmente, o desejo de propagar a imagem do Legislativo como espaço transparente e aberto ao diálogo (FUKS e FIALHO, 2009; MANGUE, 2008).

Desse modo, o PJ é pautado pela busca em ampliar o conhecimento político dos envolvidos ${ }^{3}$, desmistificar o processo legislativo e melhorar a imagem da Assembleia Legislativa. Em síntese, é esperado que, após participar do PJ, os jovens apresentem maior conhecimento político e que este conhecimento impacte nas mudanças de atitudes, em especial, na confiança institucional. No entanto, é isso mesmo que vem acontecendo?

Esse artigo parte da hipótese de que os jovens inseridos no programa estão lá por se destacarem entre os demais, principalmente, no tocante ao conhecimento político. A própria seleção dos participantes para o projeto já realiza esta clivagem. Isso acontece pois, quando as escolas não selecionam os alunos que já se destacam por possuírem conhecimento diferenciado dos demais (melhores alunos), elas deixam que a opção de participar ou não participar parta da iniciativa deles

\footnotetext{
1 Os autores agradecem a Mario Fuks por ter gentilmente cedido os dados da pesquisa "O Parlamento Jovem como espaço de socialização política?" e a Ernesto Amaral pelas críticas e sugestões.

2 Programas desse tipo podem ser observados no Congresso Nacional, nas Assembleias Estaduais, bem como em diversas Câmaras Municipais.

3 Até a edição de 2009 do PJ Mineiro as oficinas de formação política eram promovidas por monitores do curso de Ciências Sociais da PUC.MG. Este vínculo fortaleceu o objetivo do Projeto de propiciar aos participantes o aprendizado político. Devido a esta característica não se deve ver o PJ como um projeto que quer propiciar somente a aproximação afetiva da ALMG e dos participantes.
} 
próprios. No entanto, aqueles que optam por participar, em sua maioria, apresentam maior nível de conhecimento. Tais jovens, com bom nível de conhecimento político, têm posições mais sedimentadas quando comparados àqueles que não apresentaram interesse em participar do programa. Com isso, mudanças de postura provocadas por programas de educação cívica são quase imperceptíveis.

Nesse sentido, para responder às indagações propostas, iniciamos descrevendo como o Parlamento Jovem funciona e o contextualizamos diante dos projetos de educação cívica existentes no mundo. Na sequência, será apresentado como se desenvolve o processo de aprendizagem política. A terceira seção apresenta o desenho da pesquisa para que se mantenha articulada com a teoria captando as nuances das trocas de informações e estruturação do conhecimento. Por último, a análise dos dados baseia-se na hipótese central de que a sofisticação política dos participantes do PJ transforma o programa em uma arena contraproducente.

\section{Educação cívica e o Parlamento Jovem (PJ)}

O crescimento do número de projetos de educação cívica ao redor do mundo não acontece de forma padronizada ${ }^{4}$. Há experiências relatadas destes programas vinculados a escolas (JENKINS et al, 1990), organizações não governamentais (FINKEL et al, 2000; FINKEL \& SMITH, 2011), organizações externas (CAROTHERS, 1997), próprio aparato governamental (SLOMZYNSKI \& SHABAD, 1998) e instituições de ensino superior (FUKS, 2011). No entanto, apesar de fomentados por instituições distintas, apresentam como aspecto comum o desejo de munir o público alvo com informações políticas a partir de atividades, palestras, dinâmicas e vivências sobre cidadania, participação política e democracia.

O PJ de Minas Gerais surge em 2004 e, a partir daí, passa a contar com edições anuais. Ele é conduzido por monitores, alunos do curso de Ciências Sociais da PUC-MG, que são treinados por professores do departamento de Ciências Sociais da universidade e pelo corpo técnico da ALMG. A capacitação dada aos monitores visa, entre outros propósitos, possibilitar a atuação no desenvolvimento de oficinas de formação política para os alunos participantes do Programa. As cinco primeiras oficinas são teóricas e tratam dos seguintes temas: democracia, participação política, cidadania e Poder Legislativo.

Após este período, os participantes são estimulados a debater sobre o foco da edição ${ }^{5}$ e sobre a construção de "leis" que, posteriormente, serão analisadas por seus pares em plenária. Vale destacar que, em Minas Gerais, o PJ é o projeto de educação cívica que possui maior investimento financeiro e humano do Poder Legislativo estadual.

A metodologia do PJ é participativa ${ }^{6}$, com os participantes sendo desafiados a resolverem problemas políticos práticos através de dinâmicas e atividades lúdicas. Intercalado com as oficinas nas escolas, o projeto é acrescido de outras atividades, como palestras com especialistas sobre o tema da edição, visitas técnicas à ALMG e PUC, oficinas de teatro e de expressão corporal.

\footnotetext{
${ }^{4}$ Ver estudos de Finkel et al (2000) e Carothers (1997).

${ }^{5}$ Cada edição possui um tema diferente para nortear os trabalhos de todas as escolas envolvidas. Este é votado na sessão de abertura do projeto com a presença de todos os inscritos. Na edição de 2008, o tema foi: "Violência e Juventude: o jovem é provocador ou vítima?".

${ }^{6}$ Ver Finkel \& Smith (2011).
} 
SAMPAIO, T.; SIQUEIRA, M. Impacto da educação cívica sobre o conhecimento político...

Após esse processo, há a Plenária Final do projeto $^{7}$, onde as propostas são debatidas e postas em votação. Quando aprovadas pelos jovens, as propostas são entregues à Comissão de Participação Popular (CPP) e passam a tramitar na ALMG como projetos de leis.

Nesse aspecto, o PJ Mineiro diferencia-se dos demais Parlamentos Jovens do Brasil, já que a Plenária Final possibilita que o programa não seja apenas uma simulação. Com base nisso, existe a possibilidade de que ideias agregadas pelos participantes possam ser colocadas em prática podendo, em alguns casos, ganhar o status de lei.

O PJ como mecanismo de "ativação" e socialização política para a juventude

O PJ procura estimular a socialização política daqueles que se encontram envolvidos em suas arenas. Nesse sentido, ele cumpre a função de municiar e induzir os cidadãos à vida política. No entanto, vale observar que tal função é, também, compartilhada por diversas outras instituições ${ }^{8}$. Assim, o PJ vem dar complementaridade a tarefas já exercidas e que são desenvolvidas em intensidade maior por instituições como a família e a escola, e como o alcance dessas instituições é mais amplo, os programas de educação cívica são desenhados para não colidirem com valores que elas já transmitem.

Por outro lado, isso limita a atuação do PJ no debate de temas polarizados e que possam colocar em xeque normas e valores preconizados pelas escolas participantes. Além de evitar esse conflito, a tarefa do PJ torna-se ainda mais árdua pelo crescente desencanto e desinteresse sobre a política que abraça os jovens contemporâneos (JENKINS et al, 2002).

Assim, o Parlamento Jovem apresenta-se como espaço de socialização voltado a ativar em seus participantes valores como a confiança nas instituições, interesse pela política e participação cívica, além de disseminar conhecimento político como ferramenta de solidificação da democracia e criação de um ambiente político pautado pelo equilíbrio entre os atores e políticas mais justas. É necessário compreender como se estrutura o conhecimento político, como ele é tratado dentro do PJ e os meios utilizados para sua disseminação.

\section{Aprendizagem coletiva: disseminando o conhecimento político}

Para ser plena, a cidadania exige que os indivíduos tenham conhecimento sobre como funciona o ambiente político (PUTNAm, 1996; ALmond \& VerBA, 1989; FINKEL et al, 2000; FINKEL, 2003; FINKEL \& ERNST, 2005). Quanto maior for a capacidade crítica da sociedade, mais legítimas serão as decisões tomadas por quem governa. Assim, a democracia apresenta como condição primordial para sua própria existência a exigibilidade de indivíduos capacitados para fazer escolhas ${ }^{9}$.

Por mais complexa que seja a questão política, desde o eleitor mais sofisticado ao de menor conhecimento político, todos estão constantemente fazendo aferições sobre o mundo político. Tais aferições baseiam-se em conhecimento prévio ou adquirido durante o debate e satisfazem a interesses inerentes do indivíduo ou apresentados por eles como inerentes. Caso se considere que a racionalidade passa pela capacidade de tomar decisões com a expectativa de atingir algum fim determinado, infere-se

\footnotetext{
${ }^{7}$ A plenária final do PJ se realiza na plenária principal da Assembleia Legislativa de Minas Gerais.

8 As instituições desempenham papel crucial na socialização política dos indivíduos, já que esta não acontece de forma espontânea, sendo sempre dependente de estímulos para que possa ser desenvolvida (FUKS, 2010).

${ }^{9}$ No entanto, caso esses indivíduos não queiram ou não seja possível que tomem decisões a todo instante, eles devem ter pelo menos a capacidade de escolher aqueles que farão escolhas em seu lugar.
} 
que esses eleitores pautam suas ações com base em escolhas racionais. No entanto, vale observar que a escolha racional apoia-se em conhecimento. Por sua vez, a forma como é moldado o conhecimento político pode, em alguns casos, levar os cidadãos a tomarem decisões "racionais" contrárias aos seus interesses.

Nessa direção, o problema maior que frustra a capacidade do indivíduo em apontar as melhores medidas para suas vidas não reside na falta de informação, e sim, na capacidade de processar as informações disponíveis longe dos vieses. Isso ocorre porque os cidadãos não são meros receptores de informação, eles decidem qual informação deve ser descartada e qual deve ser armazenada na memória de longo prazo (LTM).

Assim, o conhecimento político representa uma série de informações organizadas e processadas de acordo com a relevância destinada pelo receptor. Tais informações são posteriormente armazenadas na memória de longo prazo e, quando despertadas, norteiam o julgamento político. Todavia, vale destacar que a aquisição de conhecimento requer que os indivíduos tenham motivação e disposição para arcar com o custo de se manterem informados.

Para induzir conhecimento aos cidadãos, as questões políticas são formatadas com affectives tags, ou seja, carregam consigo sentimentos e sua valência positiva ou negativa (tags). Como os eleitores não são uma folha em branco, já que possuem conhecimento prévio, as informações com affectives tags serão responsáveis por recuperar e se articular àquilo que já está na memória de longo prazo (LTM) tendo como passo seguinte a condução para a working memory (WM). Tal informação articulada com o conhecimento prévio do indivíduo atuando na working memory fomentará a aquisição de mais informação e norteará a ação a ser tomada por esse eleitor.

As affectives tags, em muitos casos, são responsáveis por promover julgamento político sem que haja conhecimento sistematizado atuando como sugestão. Assim sendo, "people who lack information solve enormously complex problems every day" (LUPIA \& McCUBBINS, 1998, p. 6), o que contradiz o discurso de que o baixo nível de conhecimento e a propensão a tomar decisões atreladas a sugestões afetivas seriam barreiras intransponíveis a políticas democráticas.

A ideia de que a democracia requer eleitores sofisticados com esquemas eficientes para decisões políticas não atenta para o fato de que os indivíduos estão o tempo todo fazendo inferências mais relevantes para a vida deles a partir de informações incompletas, assim como não é preciso possuir conhecimento detalhado sobre o funcionamento das aeronaves para embarcar em uma acreditando que ela possa subir e descer com segurança. No entanto, para suprir essa deficiência cognitiva, constantemente, decisões são tomadas apoiadas apenas em esquemas e heurísticas (LUPIA \& McCuBBINS, 2000).

Esquemas representam conhecimentos adquiridos por meio de experiências pessoais (CONOVER \& FELDMAN, 1984). A base do conhecimento humano é um frenético jogo de tentativa e erro. Partem daí os primeiros indicadores simples, mas extremamente úteis na infância, como, por exemplo, quente/frio, doce/salgado, alto/baixo, entre outros que protegem os indivíduos de perigos iminentes em suas vidas. Com o passar dos anos, surgem esquemas mais sofisticados que ficam armazenados na mente humana para, posteriormente, dirigir a leitura de novas informações e estruturar a ação a ser tomada (CONOVER \& FELDMAN, 1984). As affectives tags encarregam-se de promover a busca desse conhecimento na LTM. 
SAMPAIO, T.; SIQUEIRA, M. Impacto da educação cívica sobre o conhecimento político...

Desse modo, sujeitos que passaram por experiências negativas com governantes de um determinado partido como, por exemplo, desemprego provocado por crises econômicas, tenderão a se tornar relutantes à possibilidade de voltarem a ser governados por membros desse mesmo partido. Assim, cria-se um esquema de julgamento com base no passado fundado na ansiedade, e será a ansiedade a barreira para a compreensão de que o partido outrora no governo pode ter mudado a postura no presente. Entretanto, se não há nada no passado que atue como conhecimento para explicar o presente, o eleitor se apega às sugestões ou heurísticas (KUKLINSKI \& QUIRK, 2000). Essas sugestões vêm, sobretudo, da família, dos amigos, da imprensa, dos grupos de interesse e de especialistas ${ }^{10}$.

As heurísticas são atalhos utilizados para obter informações e determinar o direcionamento do processo de tomada de decisão. Elas estão relacionadas ao vínculo afetivo que o indivíduo mantém com quem fornece a sugestão, de modo que seguir sugestões dadas por adversários é uma possibilidade praticamente nula. Porém, acredita-se que aqueles que são iguais terão a mesma perspectiva e, sendo assim, a opinião deles merece ser levada em consideração. Desse modo, as heurísticas passam a ser uma estratégia racional para combater a ignorância (KUKLINSKI \& QUIRK, 2000).

Vale ainda destacar que sem motivação os indivíduos não possuem atenção para se informar. Ou seja, quando todos os esquemas dizem que a conjuntura política corresponde à expectativa traçada, não é tão necessário ir atrás dos motivos de compreender o porquê da calmaria; assim, o ponto chave do processo de aprendizagem política passa a ser como adquirir a atenção e como motivar os indivíduos a se manterem informados.

A atenção é determinada pela relevância do fato político. Por exemplo, indivíduos ligados à causa ambiental ficarão mais atentos às questões da política ambiental do que aqueles que não veem grande importância no discurso ambientalista. Nesse sentido, para fazer os indivíduos mudarem de posição é preciso primeiro conquistar a atenção deles. Conforme Lupia e McCubbins, "attention is a prerequisite for learning anything. However, attention is scarce" (LUPIA \& McCUBBINS, 1998, p. 22).

Assim, os fatos políticos que têm relevância e que passam a ser incorporados dependem da predisposição do indivíduo. No entanto, o que é preciso fazer para tornar os indivíduos receptíveis a todo tipo de informação e capazes de selecionar aquelas que são realmente condizentes com os seus interesses?

Como já dito, as crenças dos indivíduos guiam o entendimento da política, determinando, entre aquelas informações que Ihes são dirigidas, quais devem ser absorvidas e quais devem ser relevadas. Com isso, de um conjunto de informações recebidas, os eleitores geralmente selecionam apenas aquelas que lhes agradam. Por exemplo, aqueles vinculados ao governo tenderão a dar mais atenção às notícias positivas sobre o governo e, mesmo em um pacote de notícias negativas, eles encontrarão um viés para dar matiz positiva. Além disso, a crença do eleitor determinará qual o meio de comunicação ele deve utilizar para colher informação, o que reduz o papel da mídia a repositório ao qual se recorre para auxiliar no fortalecimento de uma opinião já estabelecida ${ }^{11}$.

Desse modo, o eleitor, em sua maioria, é informado, mas absorve as notícias da forma que Ihe agrada, criando justificativas para defender o que, em alguns casos, é indefensável, e é por isso que,

10 Porém, nem todas as sugestões serão aceitas ou até mesmo ouvidas, pois o eleitor tem suas convicções, e a elas se agarra e reluta em contradizê-las.

11 Essa visão tira da mídia o papel de formadora de opinião e a torna mera formatadora de opinião. 
muitas vezes, aparenta estar anestesiado a escândalos. Nesse sentido, não é por falta de informação que os eleitores, às vezes, tomam decisões errôneas, mas, sim, pela incapacidade (que nada tem a ver com o grau de escolaridade) de processar as informações disponíveis.

Uma vez que o afeto influencia na forma como as informações são processadas, sendo determinante no direcionamento do julgamento político, a empatia se apresenta como meio de conseguir a atenção e demover a opinião dos sujeitos. Empatia é a capacidade de compreender e até mesmo experimentar sentimentos nutridos por outros, ou seja, é a possibilidade de sentir a dor do outro. A empatia geralmente é obtida por meio do diálogo (DELLI CARPINI; COOK; JACOBS, 2004).

Com base nisso, nos últimos anos, para que o diálogo entre os atores produza decisões democráticas e ajustadas à realidade, foram pensadas instituições que permitam aos indivíduos trocarem experiências visando adquirir conhecimento político. No entanto, ter conhecimento não indica que os indivíduos chegarão ao consenso, mas que eles conseguirão expor com clareza o seu ponto de vista e poderão compreender as justificativas dos outros.

Apesar de nem sempre garantirem o consenso, esses espaços são profícuos por disseminarem o conhecimento, apresentarem as diferentes perspectivas que nele circulam e contribuírem para homogeneizar o conhecimento. Quanto mais homogêneo for o conhecimento político, mais equilibrada será a distribuição dos recursos políticos ${ }^{12}$. Além disso, ampliam a confiança e fortalecem a democracia. Isso ocorre pois "many political institutions allow citizens to observe a speaker's costly effort, to subject a speaker to the threat of verification (i.e., cross-examination), or to know that the speaker faces penalties for lying. These institutions can give citizens the ability to make reasoned choices" (LUPIA \& MCCUBBINS, 2000, p. 49).

Decisões democráticas não necessariamente são justas. Para serem justas não é necessário apenas passar pelo crivo de todos, mas, sobretudo, que os julgamentos a pautem sobre informações verídicas e de fácil compreensão a todos. Se as informações se tornam exotéricas, as decisões passam para as mãos daqueles habilitados para decifrá-las.

No Parlamento Jovem, a pesquisa demonstra que informações exotéricas se tornam o principal empecilho, pois elas determinam como se dá a participação, ou seja, quem não possui um conjunto de códigos específicos para atuar no ambiente do Parlamento não tem capacidade mínima de participação. Dessa forma, o PJ transforma-se em uma arena onde o conhecimento político é essencial para determinar quem fica, pois, como já foi dito, ele é aberto a quem desejar participar, dentro das escolas selecionadas. No entanto, as distorções do conhecimento entre os participantes não são levadas em consideração.

Como apresentado anteriormente, os indivíduos absorvem informações da maneira que melhor Ihes convier. Neste sentido, a influência do afeto determina quais questões têm relevância, o que deve ser analisado com mais cautela e o que deve ser descartado. No Parlamento Jovem, os participantes são envolvidos em um processo de aprendizagem comum para todos. No entanto, os resultados obtidos são bem distintos. O objetivo do PJ é aumentar a capacidade cívica dos indivíduos envolvidos, entretanto, em alguns casos, o que acontece é exatamente o contrário.

12 Vale ressaltar que aqueles com mais recursos políticos têm maior facilidade em obter conhecimento e decifrar o mundo político. 
SAMPAIO, T.; SIQUEIRA, M. Impacto da educação cívica sobre o conhecimento político...

Dito isto, como o Parlamento Jovem lida com os diferentes níveis de conhecimento dentro de sua estrutura? Ele é capaz de diminuir a clivagem de conhecimento entre aqueles que dele participam?

\section{Considerações metodológicas e tratamento dos dados}

Os dados utilizados neste artigo fazem parte de um quase-experimento realizado com toda a coorte do Parlamento Jovem de Minas Gerais, edição de $2008^{13}$, contando também com grupo de controle $^{14}$. Desta forma, os dados aqui examinados estruturam-se em quatro níveis de informações: participantes e não participantes (tratamento e controle, respectivamente) nos tempos 1 e 2 (antes e após as atividades do projeto).

A análise dos dados desenvolveu-se com base em quatro variáveis dependentes formadas por índices que delimitam o processo de aprendizagem do PJ, quais sejam: Índice de Conhecimento sobre a Democracia; Índice de Conhecimento sobre Instituições do Poder Legislativo e Índice do Conhecimento do Espectro Ideológico Partidário. No final, os três índices formam o Índice de Conhecimento Geral ${ }^{15}$.

Como a formação política proposta pelo Projeto Parlamento Jovem está focada em quatro diretrizes - participação política, cidadania, democracia e poder legislativo, dois índices aqui utilizados fazem parte dos temas trabalhados diretamente pelo programa: Índice de Conhecimento sobre Democracia e Índice de Conhecimento sobre Instituições do Poder Legislativo. No tocante ao conhecimento adquirido sobre espectro ideológico partidário, espera-se que ele decorra de ganho indireto, pois só é conquistado mediante o interesse do participante em se informar para além do oferecido pelo PJ. Este desenho dos índices parciais para originar o Índice de Conhecimento Geral foi pensado exatamente com o objetivo de captar a direção do aprendizado, dando ênfase aos temas trabalhados.

Como variáveis independentes para explicar a cognição/conhecimento político entre os grupos de tratamento e controle, uma segunda bateria de índices sobre a importância da política para os pesquisados é utilizada (ver Anexo 2). Novamente são criados quatro índices, três parciais: Índice de Interesse por Política; Índice de Exposição às Informações Políticas e Índice de Percepção da Influência da Política no Cotidiano. Em conjunto, eles formam o Índice Geral de Importância Política.

A hipótese é que aqueles que atribuem "maior importância da política para suas vidas" têm uma dimensão afetiva com ela (affective tags), o que aumenta seu conhecimento ao longo do tempo. A partir desta hipótese, também foram observadas as diferenças entre o grupo de tratamento e o de controle.

Como estratégia metodológica, primeiramente, realizamos uma análise descritiva dos índices de conhecimento levando em consideração os grupos de tratamento e controle nos tempos 1 e 2 . Testes de média e desvio-padrão são apresentados para subsidiar com significância estatística as

\footnotetext{
13 O banco de dados utilizado pertence à pesquisa "O parlamento Jovem como espaço de socialização política?", coordenada pelo professor Mario Fuks, do Departamento de Ciência Política (DCP) da Universidade Federal de Minas Gerais (UFMG).

14 O quase-experimento foi executado com pré-teste e pós-teste. Não foi possível estabelecer randomização, já que os participantes do PJ não são escolhidos de forma aleatória. O emparelhamento deu-se por meio da seleção de estudantes com perfil próximo àqueles que participam do PJ. Os estudantes não-participantes do PJ (175 no total) escolhidos para participar da pesquisa foram agrupados no grupo de controle. Já os participantes do PJ (176 jovens) formam o grupo de tratamento. Vale ressaltar que durante toda a análise os termos "grupo de participantes" e "grupo de tratamento" serão utilizados como sinônimos, assim como "grupo dos não participantes" e "grupo de controle". Vale destacar o predomínio de jovens de escolas particulares de elite (99) e jovens de escolas públicas militares (98).
}

${ }^{15}$ A descrição da construção metodológica dos índices está disponível com detalhes no Anexo 1. 
interpretações aqui trabalhadas. Em seguida, expomos a tabela de contingência entre o Índice Geral de Conhecimento e o Índice Geral de Importância Política, que permite visualizar com clareza a diferença dos ganhos de aprendizado entre aqueles que possuem affective tags e os que não possuem, sendo possível comparar os grupos ao longo do tempo. Por fim, para mensurar a magnitude dos efeitos do PJ sobre o conhecimento, realizamos uma análise de regressão linear de Mínimos Quadrados Ordinários (MQO).

A análise de regressão agrega novas variáveis independentes já consideradas pela literatura como preditoras de ganhos de aprendizagem. Segundo Fuks (2011), os espaços socializadores em níveis primários (família) e secundários (ex.: escola) são preponderantes para distinguir sociologicamente aqueles indivíduos que alcançarão maiores níveis de conhecimento. Não obstante, este mesmo autor salienta que isto não é determinístico, pois ainda é necessário considerar atributos, habilidades e predisposições individuais. Estas variáveis são levadas em consideração e esquematizadas da seguinte maneira:

Quadro 1

Variáveis Independentes

\begin{tabular}{|l|l|}
\hline \multirow{4}{*}{ Atributos Individuais } & Sexo \\
\cline { 2 - 2 } & Ano do Ensino Médio \\
\cline { 2 - 2 } & Atribuição de importância à política \\
\cline { 2 - 2 } & Propensão a debater \\
\hline \multirow{2}{*}{ Atributos da família } & Escolaridade dos pais \\
\cline { 2 - 2 } & Posição de elite \\
\hline \multirow{4}{*}{ Ambientes Socializadores } & Escola com Grêmio \\
\cline { 2 - 2 } & Tipo de Escola \\
\cline { 2 - 2 } & Experiência de socialização anterior ao PJ \\
\hline
\end{tabular}

Fonte: Banco de dados da pesquisa "O parlamento Jovem como espaço de socialização política?"

Nessa perspectiva, o grau de conhecimento político é uma função das variáveis que compõem os atributos individuais, familiares e ambientes socializadores. A forma matemática de escrever esta função é a que segue:

$$
y=f\left(x_{1}, x_{2}, x_{3}, x_{4}, x_{n}\right)
$$

Ou seja:

Conhecimento $=f$ (Participante, Masculino, Aluno do Terceiro Ano, Alta importância, Propensão a debater, Escolaridade dos pais, Posição de elite, Escola com Grêmio, Escola privada, Experiência de socialização anterior ao PJ). 
SAMPAIO, T.; SIQUEIRA, M. Impacto da educação cívica sobre o conhecimento político...

Para mensurar o impacto de cada uma das variáveis sobre o conhecimento político é feita análise de regressão. Além disso, para melhor compreensão das variáveis, foi utilizada a correlação de Pearson. A análise de correlação indica que, para a estimação com estas variáveis, o modelo não terá problema com o pressuposto de multicolinearidade, uma vez que não se tem correlações muito fortes. No entanto, para esta afirmação ser realizada com propriedade, realizou-se o teste VIF e constatou-se que o pressuposto da não colinearidade ${ }^{16}$ foi atendido. A equação da regressão e as hipóteses levando em consideração cada variável são as seguintes:

\title{
$Y=\beta_{0}+\beta_{1} X_{1}+\beta_{2} X_{2}+\beta_{3} X_{3} \ldots \beta_{n} X_{n}$
}

\author{
Conhecimento Político $=\beta_{0}+\beta_{1}$ Participante $+\beta_{2}$ Masculino $+\beta_{3}$ Aluno do Terceiro Ano $+\beta_{4}$ Alta \\ importância $+\beta_{5}$ propensão a debater $+\beta_{6}$ Escolaridade dos pais $+\beta_{7}$ Posição de elite $+\beta 8$ \\ Escola com Grêmio $+\beta_{8}$ Escola privada $+\beta_{9}$ Experiência de socialização $+\beta_{10}$ Experiência de \\ socialização anterior ao PJ
}

Hipóteses para o modelo de regressão:

1. Participantes possuem maiores conhecimentos em relação aos não participantes. Isto devido aos inscritos no PJ já serem alunos que possuem interesse e conhecimento sobre política prévios mais acentuados do que aqueles que não se interessam em participar do projeto.

2. Homens tendem a possuir maiores conhecimento político, interesse e percepção da influência da política sobre suas vidas do que as mulheres (VERBA; BURNS; SCHLOZMAN, 1997).

3. Alunos do terceiro ano possuem maiores conhecimento sobre política do que os do segundo ano. Segundo Sears e Valentino (1997), o processo de socialização política dos jovens inicia mediante a primeira experiência do voto e, como os alunos do terceiro ano têm, pelo menos, entre 17 e 18 anos de idade, já são abrangidos pelo sufrágio. Como em 2008 - ano de realização da pesquisa · aconteceram eleições municipais, a maior parte destes estudantes inseriu-se pela primeira vez neste ambiente de tomada de decisões, o que, "naturalmente", provoca a busca por mais informações sobre política.

4. Os alunos que possuem propensão a debater adquirem maior conhecimento do que aqueles que não possuem propensão para debater. Em uma arena democrática de plenária - ambiente proporcionado pelo PJ - onde o discurso e a mobilização são cruciais para a defesa dos interesses políticos defendidos, o debate deve ser embasado sobre o conhecimento. Caso contrário, o adversário com conhecimento sólido terá maiores chances de mobilizar a opinião dos demais. Desta forma, aqueles participantes que se posicionam no debate político buscam reforçar seus argumentos mediante a busca de conhecimentos. 5. Aqueles que percebem alta importância na política possuem maior conhecimento sobre o assunto do que aqueles que não possuem. Esta formulação é apresentada como hipótese norteadora deste artigo. No entanto, faz-se necessário mensurar a magnitude de seu impacto sobre o conhecimento político. Em

${ }^{16}$ Apesar de já se perceber um indicativo pelos coeficientes de Pearson de que não há colinearidade entre as variáveis, também foi realizado o teste VIF (Fator de Inflação de Variância). Nele se observou que os valores das variáveis foram menores do que 5 $(\mathrm{VIF}<5)$ e a média dos fatores foi de 1,73 . Isto comprova que o pressuposto da não colinearidade é observado neste modelo. 
outras palavras, quanto maior o envolvimento afetivo com a política (afecttive tags), maior o conhecimento alcançado.

6. A escolaridade dos pais gera ganho positivo sobre o conhecimento dos filhos. Assim, quanto maior a escolaridade dos pais maior o conhecimento político dos filhos.

7. Pais que possuem posição de elite impactam o conhecimento dos filhos por possibilitarem a eles acesso diversificado às informações e estimularem a socialização política, ressaltando sempre as questões políticas que interferem diretamente no cotidiano familiar. Desse modo, famílias cujos pais são politizados direcionam, por exemplo, a identificação partidária e estruturam a visão que os filhos terão da política (JENNINGS \& NIEMI, 1968; TEDIN, 1974).

8. Alunos de escolas privadas são mais propensos ao conhecimento político do que alunos de escola pública. Os primeiros são estimulados a manter visão crítica sobre a política e a se posicionarem como líderes, já os segundos não são encorajados a debates políticos; para eles, a política é algo distante e nocivo às suas vidas. Além disso, os alunos de escolas privadas geralmente dispõem de mais recursos materiais e tempo para se informar.

9. O fato de possuir outras experiências socializadoras é um indicativo de sujeitos que demonstram interesse pela política e desejam ampliar o conhecimento político. Assim, entende-se que ambientes socializadores estimulam o compartilhamento de valores, símbolos e conhecimentos entre os frequentadores destes ambientes e a busca por novos meios como, por exemplo, o PJ para compartilhar a aprendizagem adquirida.

Análise dos Resultados

O Índice de Conhecimento sobre Democracia mede a quantidade de conhecimento dos pesquisados sobre regras básicas do sistema político. A Tabela 1, formada pelo somatório dos acertos sobre as questões democráticas, mostra, tanto através da soma, quanto pela média, que os grupos de tratamento (não participantes) e controle (participantes) ampliaram o conhecimento ao longo do tempo.

A soma do grupo de controle passa de 801 para 809, a média passa de 4,767 para 4,816 (aumento de 0,0476). O grupo de tratamento, no tempo 1, começa com menos acertos do que o grupo de controle (soma 790 acertos contra os 801). Nesse sentido, o Índice de Conhecimento sobre a Democracia aponta que os participantes alcançaram ganhos ínfimos em comparação àqueles que não participaram do PJ. Não há, também, como inferir que esses ganhos se deveram apenas ao PJ, pois o teste de média não apontou significância entre as diferenças das médias ( $p=0,398$ ). Quanto à capacidade do projeto em nivelar o conhecimento entre os seus participantes e deixá-los como um grupo mais homogêneo, também não foi estatisticamente significante ao realizar o teste de desvio-padrão, tomando como base o grupo de controle $(p=0,778)$. 
SAMPAIO, T.; SIQUEIRA, M. Impacto da educação cívica sobre o conhecimento político...

Tabela 1

Descrição de indicadores do conhecimento político MG (2008)

\begin{tabular}{|c|c|c|c|c|c|c|}
\hline & & & Soma & Média & $\begin{array}{l}\text { Desvio } \\
\text { Padrão }\end{array}$ & Variância \\
\hline \multirow{6}{*}{$\begin{array}{l}\text { Conhecimento sobre } \\
\text { democracia }\end{array}$} & \multirow{2}{*}{$\begin{array}{l}\text { Grupo de } \\
\text { Controle }\end{array}$} & Tempo 1 & 801 & 4,7679 & 0,99684 & 0,994 \\
\hline & & Tempo 2 & 809 & 4,8155 & 1,0068 & 1,014 \\
\hline & \multirow{2}{*}{$\begin{array}{l}\text { Grupo de } \\
\text { Tratamento }\end{array}$} & Tempo 1 & 790 & 4,7305 & 1,06101 & 1,126 \\
\hline & & Tempo 2 & 810 & 4,8503 & 1,02163 & 1,044 \\
\hline & \multirow{2}{*}{ Geral } & Tempo 1 & 1668 & 4,9791 & 1,08729 & 1,182 \\
\hline & & Tempo 2 & 1715 & 5,1194 & 1,0196 & 1,04 \\
\hline \multirow{6}{*}{$\begin{array}{l}\text { Conhecimento sobre } \\
\text { Instituições do Poder } \\
\text { Legislativo }\end{array}$} & \multirow{2}{*}{$\begin{array}{l}\text { Grupo de } \\
\text { Controle }\end{array}$} & Tempo 1 & 690 & 4,1071 & 1,40161 & 1,964 \\
\hline & & Tempo 2 & 672 & 4 & 1,53209 & 2,347 \\
\hline & \multirow{2}{*}{$\begin{array}{l}\text { Grupo de } \\
\text { Tratamento }\end{array}$} & Tempo 1 & 717 & 4,2934 & 1,23362 & 1,522 \\
\hline & & Tempo 2 & 721 & 4,3174 & 1,38881 & 1,929 \\
\hline & \multirow{2}{*}{ Geral } & Tempo 1 & 1407 & 4,2 & 1,32186 & 1,747 \\
\hline & & Tempo 2 & 1393 & 4,1582 & 1,46885 & 2,158 \\
\hline \multirow{6}{*}{$\begin{array}{l}\text { Conhecimento do Espectro } \\
\text { Ideológico Partidário }\end{array}$} & \multirow{2}{*}{$\begin{array}{l}\text { Grupo de } \\
\text { Controle }\end{array}$} & Tempo 1 & 242 & 1,4405 & 1,59228 & 2,535 \\
\hline & & Tempo 2 & 287 & 1,7083 & 1,59473 & 2,543 \\
\hline & \multirow{2}{*}{$\begin{array}{l}\text { Grupo de } \\
\text { Tratamento }\end{array}$} & Tempo 1 & 350 & 2,0958 & 1,54543 & 2,388 \\
\hline & & Tempo 2 & 342 & 2,0479 & 1,73833 & 3,022 \\
\hline & \multirow{2}{*}{ Geral } & Tempo 1 & 592 & 1,7672 & 1,60075 & 2,562 \\
\hline & & Tempo 2 & 629 & 1,8776 & 1,67402 & 2,802 \\
\hline
\end{tabular}

Fonte: Pesquisa "O parlamento Jovem como espaço de socialização política?"

O Índice de Conhecimento sobre Instituições do Poder Legislativo mensura a capacidade dos entrevistados em compreender como se configura o Legislativo. Nesse índice, os participantes apresentam o mesmo tímido crescimento no conhecimento. Na Tabela 1, é possível perceber um leve salto da média do conhecimento do grupo tratamento de 4,29 para 4,31, seguido por um leve aumento no desvio-padrão ${ }^{17}$. Esses fatores apontam para a polarização do conhecimento, ou seja, certo grupo de participantes do PJ ganha conhecimento, enquanto outra parcela mantém estável ou perde conhecimento.

No cômputo geral, a Tabela 1 demonstra certa capacidade do PJ em, pelo menos, manter o conhecimento prévio dos participantes sobre o Legislativo, já que o grupo de controle encolheu abruptamente o conhecimento (690 no "tempo 1" para 672 no "tempo 2"). Por outro lado, vale ressaltar que os participantes são sujeitos politicamente mais sofisticados do que os não participantes. Assim, dificilmente, mesmo que fora do PJ, o conhecimento deles seria reduzido, já que é um público que busca constantemente manter-se informado.

A Tabela 1 apresenta ainda o Índice sobre o Espectro Ideológico Partidário, que mede o conhecimento dos pesquisados sobre a política partidária e sobre o posicionamento dos partidos no

\footnotetext{
${ }^{17} \mathrm{~A}$ diferença entre as médias é significativa segundo o teste de média $(p=0,023)$
} 
ambiente político. Esse índice denota certa deficiência do PJ em ampliar o conhecimento, pois o grupo não participante conseguiu ganhos expressivos, enquanto os participantes "desaprenderam".

Ainda na Tabela 1, vemos que a média de acertos do grupo de controle sobe de 1,441 para 1,708 , já a média do grupo tratamento, que era 2,09 passou para 2,04. Além disso, há aumento expressivo no desvio-padrão e variância, indicando uma tendência de diferenciação intragrupos, ou seja, o conhecimento passa a ser mais disperso entre os participantes. Essa diferenciação do desvio-padrão entre os grupos é significativa para $90 \%$ de confiança, ou seja, o $p=0,084$.

Desse modo, quando observado o Índice de Conhecimento Geral, percebe-se que 70,9\% dos participantes classificavam-se com muito conhecimento sobre a política, enquanto os não participantes com muito conhecimento representavam $70,6 \%$. Porém, no decorrer do programa, houve grande queda de conhecimento entre os participantes. Com isso, no final do programa, apenas 65,2\% encaixavam-se entre os de muito conhecimento, obtendo assim redução de $5,2 \%$, enquanto a redução dos não participantes foi de apenas $3,6 \%$. Portanto, os não participantes terminam o período com mais conhecimento do que aqueles que participaram. O Gráfico 1 ilustra esse cenário:

Gráfico 1

Indivíduos com muito conhecimento (\%)

MG (2008)

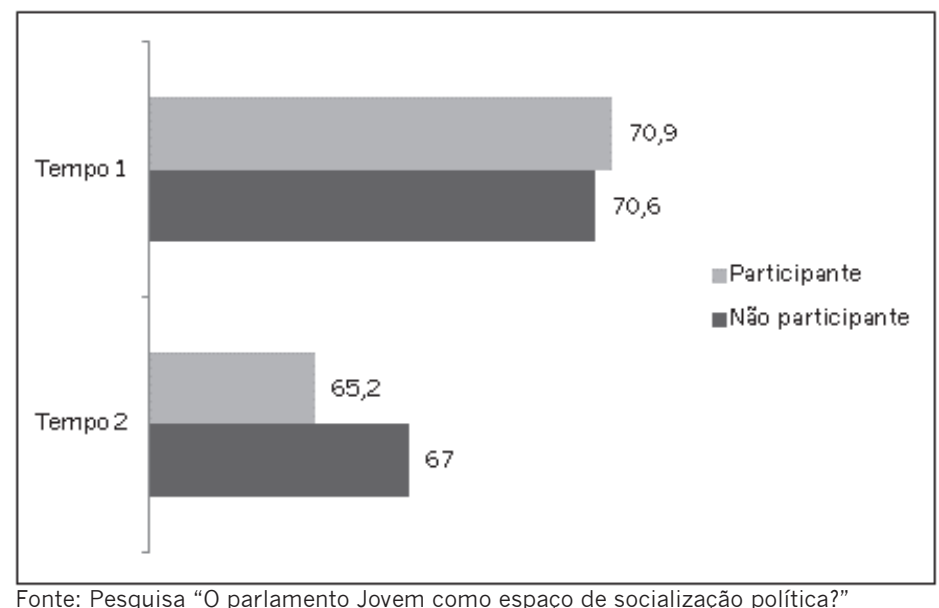

Dessa forma, fica clara a falha em possibilitar a disseminação de conhecimento sobre a política para os envolvidos no PJ. Mas o que leva a esse cenário desastroso? Ele é uniforme entre todos os participantes?

O que dirige a forma que se dá o conhecimento é, sem dúvida, a ligação afetiva que os indivíduos mantêm com as questões políticas. Nesse sentido, dentro do PJ, aqueles com maior interesse e, consequentemente, maior conhecimento, dominam o ambiente, cabendo aos que possuem baixo interesse e baixo conhecimento limitarem-se ao papel de espectadores. Nesse sentido, o conhecimento do grupo com maior interesse cresce e o do grupo com menor interesse fica estagnado ou até mesmo sofre redução. Na Tabela 2, fica perceptível como se estabelece essa relação: 
SAMPAIO, T.; SIQUEIRA, M. Impacto da educação cívica sobre o conhecimento político...

Tabela 2

Cruzamento entre o Nível de Importância da Política e o Conhecimento MG (2008)

\begin{tabular}{|c|c|c|c|c|}
\hline \multicolumn{2}{|r|}{ ÍNDICE DE IMPORTÂNCIA } & Soma & Média & Desv. Pad. \\
\hline \multirow{8}{*}{ Pouco importante } & Índice conhecimento democracia - Tempo 1 & 14,00 & 2,0000 & 0,81650 \\
\hline & Índice conhecimento democracia - Tempo 2 & 11,00 & 1,5714 & 0,97590 \\
\hline & Índice conhecimento partidário - Tempo 1 & 1,00 & 0,1429 & 0,37796 \\
\hline & Índice conhecimento partidário - Tempo 2 & 0,00 & 0,0000 & 0,00000 \\
\hline & Índice conhecimento legislativo - Tempo 1 & 16,00 & 2,2857 & 0,48795 \\
\hline & Índice conhecimento legislativo - Tempo 2 & 15,00 & 2,1429 & 1,34519 \\
\hline & Índice conhecimento geral - Tempo 1 & 10,00 & 1,4286 & 0,53452 \\
\hline & Índice conhecimento geral - Tempo 2 & 4,00 & 0,5714 & 0,53452 \\
\hline \multirow{8}{*}{ Importante } & Índice conhecimento democracia - Tempo 1 & 231,00 & 2,4574 & 0,78514 \\
\hline & Índice conhecimento democracia - Tempo 2 & 236,00 & 2,5106 & 0,68383 \\
\hline & Índice conhecimento partidário - Tempo 1 & 111,00 & 1,1809 & 1,00496 \\
\hline & Índice conhecimento partidário - Tempo 2 & 109,00 & 1,1596 & 1,11975 \\
\hline & Índice conhecimento legislativo - Tempo 1 & 260,00 & 2,7660 & 0,70977 \\
\hline & Índice conhecimento legislativo - Tempo 2 & 268,00 & 2,8511 & 0,94990 \\
\hline & Índice conhecimento geral - Tempo 1 & 91,00 & 0,9681 & 0,92110 \\
\hline & Índice conhecimento geral - Tempo 2 & 114,00 & 1,2128 & 0,52614 \\
\hline \multirow{8}{*}{ Muito importante } & Índice conhecimento democracia - Tempo 1 & 176,00 & 2,6667 & 0,64051 \\
\hline & Índice conhecimento democracia - Tempo 2 & 188,00 & 2,8485 & 0,43826 \\
\hline & Índice conhecimento partidário - Tempo 1 & 120,00 & 1,8182 & 0,94314 \\
\hline & Índice conhecimento partidário - Tempo 2 & 122,00 & 1,8485 & 1,08475 \\
\hline & Índice conhecimento legislativo - Tempo 1 & 192,00 & 2,9091 & 0,85444 \\
\hline & Índice conhecimento legislativo - Tempo 2 & 198,00 & 3,0000 & 0,78446 \\
\hline & Índice conhecimento geral - Tempo 1 & 34,00 & 0,5152 & 0,84567 \\
\hline & Índice conhecimento geral - Tempo 2 & 98,00 & 1,4848 & 0,61375 \\
\hline
\end{tabular}

Fonte: Pesquisa "O parlamento Jovem como espaço de socialização política?"

A partir da observação dos dados para os grupos de tratamento e de controle, pode-se inferir que os ganhos de conhecimento acontecem, mormente, entre aqueles que possuem dimensão afetiva com a política. Assim, os indivíduos que possuem níveis elevados de conhecimento logo dominam o espaço sem que haja possibilidade de criar um ambiente de conhecimento próximo a ser homogêneo.

Como já apresentado, o conhecimento se deposita na memória de longo prazo (LTM) com suas respectivas affective tags e, quando despertado pelo afeto, é transportado para a memória de trabalho (WM). A aprendizagem é, então, dependente da capacidade de atrair a atenção que, por sua vez, se relaciona ao conhecimento prévio. Assim, pode-se afirmar que "a cornerstone of any model of political reasoning is the citizen's preexisting knowledge and predilections" (LODGE \& TABER, 2005, p. 480). 
Predileções que irão, outrossim, determinar em quem confiar quando for travado algum debate ou surgir a necessidade de tomar posição. Dessa forma, aqueles com conhecimento mais baixo adotam a opinião daqueles em quem eles confiam. Com isso, não raro, os membros de uma mesma escola terão opinião assemelhada como também aqueles de escolas similares (públicas de baixa renda, particulares, etc.) tenderão a ter opinião parecida. Neste sentido, modelos de comportamento que são encarados como apenas provenientes da formação escolar e renda dos indivíduos inseridos no PJ devem-se também, em parte, à confiança mantida entre os mais próximos.

Dessa forma, os sujeitos que ingressam no PJ com muito interesse pela política são aqueles que obtêm maiores ganhos de conhecimento, já que são mais vigilantes às condicionantes do ambiente. Já os que não dispensam muita atenção à política (baixo interesse) são aqueles com os piores ganhos.

Além disso, aqueles com interesse maior pela política, com o passar do tempo, tendem a manter níveis de conhecimento mais homogêneos. Desse modo, ao observar, na Tabela 2, o desviopadrão do Índice de Conhecimento, verifica-se que no tempo 1 ele era de 0,845, caindo para 0,613 no tempo 2, já os que demonstraram pouco interesse mantiveram o mesmo desvio-padrão nos tempos 1 e 2 $(0,534)$.

Nesse formato, entendemos que os sujeitos, ao ingressarem no PJ, apesar da baixa idade, fazem-no com certa bagagem de conhecimento que não deve ser desprezada. Tal bagagem é reflexo, sobretudo, de sugestões familiares e do ambiente escolar, mas que no PJ ganham o impacto da confiança mútua. Por sua vez, a confiança vincula-se ao afeto, pois a possibilidade de empatia e troca de experiências é maior entre aqueles com perspectivas e interesses compartilhados. Todavia, qual o impacto do Parlamento Jovem quando se consideram todas estas variáveis que aumentam ou diminuem a probabilidade de os indivíduos serem informados sobre política?

Para mensurar a magnitude explicativa destas variáveis e verificar o impacto do PJ sobre o conhecimento político, foi realizado um modelo de regressão de Mínimos Quadrados Ordinários (MQO). Vale relembrar que nosso modelo explicativo possui três dimensões: características individuais (sexo, escolaridade, atribuição de importância à política e propensão a debater); ambiente familiar (escolaridade dos pais e classe social) e demais ambientes socializadores (escola pública ou privada, possuir espaços de participação como grêmios estudantis).

Para visualizar com maior clareza a relação entre as variáveis, a Tabela 3 apresenta os coeficientes de correlação de Pearson. A interpretação é realizada da seguinte forma: quanto mais perto de 1 ou -1, maior o grau de correlação, quanto mais se aproxima do "0", menos correlacionadas as variáveis estão. 
SAMPAIO, T.; SIQUEIRA, M. Impacto da educação cívica sobre o conhecimento político...

Tabela 3

Coeficiente de correlação de Pearson entre variáveis de interesse MG (2008)

\begin{tabular}{|c|c|c|c|c|c|c|c|c|c|c|c|}
\hline & 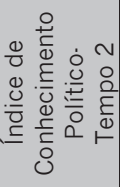 & 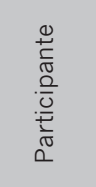 & 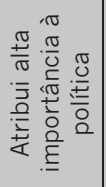 & 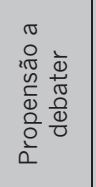 & 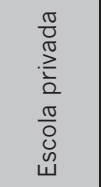 & 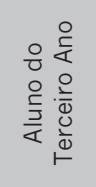 & 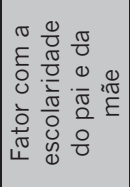 & $\begin{array}{l}\frac{\varepsilon}{0} \\
\text { है } \\
\text { 이 }\end{array}$ & 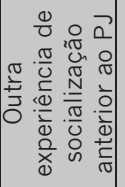 & 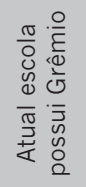 & $\mid \begin{array}{l}0 \\
0 \\
0 \\
2 \pi \\
20 \\
\frac{0}{n} \\
0 \\
0 \\
0\end{array}$ \\
\hline $\begin{array}{l}\text { Índice de } \\
\text { Conhecimento } \\
\text { Político - } \\
\text { Tempo } 2 \\
\end{array}$ & 1 & & & & & & & & & & \\
\hline Participante & 0,107 & 1 & & & & & & & & & \\
\hline $\begin{array}{l}\text { Atribui alta } \\
\text { importância à } \\
\text { política }\end{array}$ & $0,248^{* *}$ & $0,109^{*}$ & 1 & & & & & & & & \\
\hline $\begin{array}{l}\text { Propensão a } \\
\text { debater }\end{array}$ & $0,239^{* *}$ & $.0,033$ & 0,078 & 1 & & & & & & & \\
\hline $\begin{array}{l}\text { Escola } \\
\text { privada }\end{array}$ & $0,343^{* *}$ & $-0,009$ & $0,226^{* *}$ & 0,077 & 1 & & & & & & \\
\hline $\begin{array}{l}\text { Aluno do } \\
\text { Terceiro Ano }\end{array}$ & $0,192^{* *}$ & 0,001 & 0,032 & 0,060 & 0,078 & 1 & & & & & \\
\hline $\begin{array}{l}\text { Fator com a } \\
\text { escolaridade } \\
\text { do pai e da } \\
\text { mãe }\end{array}$ & $0,416^{* *}$ & 0,022 & $0,274^{* *}$ & $0,139^{*}$ & $0,653^{* *}$ & $\cdot 0,021$ & 1 & & & & \\
\hline Homem & $0,217^{* *}$ & 0,002 & 0,010 & 0,031 & 0,097 & $\cdot 0,024$ & 0,034 & 1 & & & \\
\hline $\begin{array}{l}\text { Outra } \\
\text { experiência } \\
\text { de } \\
\text { socialização } \\
\text { anterior ao PJ }\end{array}$ & $0,185^{* *}$ & 0,043 & 0,083 & $0,120^{*}$ & $0,148^{* *}$ & 0,102 & $0,178^{* *}$ & $.0,014$ & 1 & & \\
\hline $\begin{array}{l}\text { Atual escola } \\
\text { possui } \\
\text { Grêmio }\end{array}$ & $0,270^{* *}$ & 0,090 & $0,234^{* *}$ & 0,073 & $0,128^{*}$ & $.0,112^{*}$ & $0,323^{* *}$ & 0,009 & 0,102 & 1 & \\
\hline $\begin{array}{l}\text { Posição de } \\
\text { elite }\end{array}$ & $0,278^{* *}$ & $.0,039$ & $0,176^{* *}$ & $0,140^{*}$ & $0,632^{* *}$ & 0,005 & $0,577^{* *}$ & 0,060 & $0,149^{* *}$ & $0,120^{*}$ & 1 \\
\hline
\end{tabular}

**. A correlação é significante para um nível do $\alpha$ de 0,01

* A correlação é significante para um nível do $\alpha$ de 0,05.

Fonte: Pesquisa "O parlamento Jovem como espaço de socialização política?"

Os coeficientes de Pearson mostram que a variável mais correlacionada com o grau de conhecimento dos adolescentes é a escolaridade dos pais $(0,416)$. Esta relação é positiva e significativa ao nível de confiança de $95 \%$, por isso, pode-se considerar que, quanto maior a escolaridade dos pais, maiores serão as chances de os filhos serem bem informados. Com exceção das variáveis participantes, alunos do terceiro ano e outras experiências socializadoras, as demais possuem um nível baixo de correlação; no entanto, devem ser consideradas como preditoras de conhecimento.

O modelo de regressão (Tabela 4) é significativo a um nível de confiança de 99\% ( $p<0,001)$ e seu poder explicativo sobre as variáveis que influenciam a variação do conhecimento político é de 30,4\% $\left(R^{2}=0,304\right)$. Ao todo são consideradas 670 observações, sendo 335 no tempo 1 e 335 no tempo 2 . 
OPINIÃO PÚBLICA, Campinas, vol. 19, n², novembro, 2013, p. 380-402

Tabela 4

Coeficientes e erros-padrão estimados por modelo de mínimos quadrados ordinários para condicionantes que afetam o Índice Geral de Conhecimento

MG (2008)

\begin{tabular}{|c|c|c|c|}
\hline & Variáveis independentes & $\begin{array}{c}\text { Conhecimento } \\
\text { Político } \\
\text { Beta } \\
\end{array}$ & $\begin{array}{c}\text { Conhecimento } \\
\text { Político } \\
\text { Beta Padronizado }\end{array}$ \\
\hline \multirow{6}{*}{ Parlamento Jovem } & \multirow{2}{*}{ Participante } & $0,623^{* * *}$ & 0,103 \\
\hline & & $(0,282)$ & \\
\hline & \multirow{2}{*}{ Tempo 2} & $1,168^{* * *}$ & 0,192 \\
\hline & & $(0,331)$ & \\
\hline & \multirow{2}{*}{ Interação Participante x Tempo (Efeito do PJ) } & $-0,192$ & $-0,027$ \\
\hline & & $(0,397)$ & \\
\hline \multirow{12}{*}{ Atributos Individuais } & Feminino & Referência & Referência \\
\hline & \multirow{2}{*}{ Masculino } & $1,130 * * *$ & 0,181 \\
\hline & & $(0,204)$ & \\
\hline & Aluno do Segundo Ano & Referência & Referência \\
\hline & \multirow{2}{*}{ Aluno do Terceiro Ano } & $1,724^{* * *}$ & 0,171 \\
\hline & & $(0,331)$ & \\
\hline & Baixa e Média Importância & Referência & Referência \\
\hline & \multirow{2}{*}{ Alta importância } & $1,279 * * *$ & 0,209 \\
\hline & & $(0,272)$ & \\
\hline & Não propensão a debater & Referência & Referência \\
\hline & \multirow{2}{*}{ Propensão a debater } & $0,446 * *$ & 0,071 \\
\hline & & $(0,211)$ & \\
\hline \multirow{5}{*}{ Atributos da Família } & \multirow{2}{*}{ Fator de escolaridade dos pais } & $1,144^{* * *}$ & 0,331 \\
\hline & & $(0,157)$ & \\
\hline & Posição sem ser de elite & Referência & Referência \\
\hline & \multirow{2}{*}{ Posição de elite } & $-0,239$ & $-0,039$ \\
\hline & & $(0,268)$ & \\
\hline \multirow{9}{*}{ Ambientes Socializadores } & Escola sem Grêmio Estudantil & Referência & Referência \\
\hline & \multirow{2}{*}{ Escola com Grêmio Estudantil } & 0,040 & 0,022 \\
\hline & & $(0,060)$ & \\
\hline & Escola Pública & Referência & Referência \\
\hline & \multirow{2}{*}{ Escola Privada } & $0,499 *$ & 0,082 \\
\hline & & $(0,292)$ & \\
\hline & $\begin{array}{l}\text { Não possui experiências socializadoras } \\
\text { anterior ao PJ }\end{array}$ & Referência & Referência \\
\hline & \multirow{2}{*}{ Experiência de socialização anterior ao PJ } & $0,697^{* *}$ & 0,074 \\
\hline & & $(0,319)$ & \\
\hline
\end{tabular}

Obs.: O Erro Padrão de cada coeficiente está entre parênteses.

Nota: $\mathrm{R}^{2}=0,322, \mathrm{~N}=323 * \mathrm{p}<0,1 ;{ }^{* *} \mathrm{p}<0,05 ;{ }^{* * *} \mathrm{p}<0,01$.

Fonte: Pesquisa "O parlamento Jovem como espaço de socialização política?"

De acordo com a Tabela 4, ao se fazer a análise dos coeficientes, a afirmativa de que os participantes do Parlamento Jovem já começam o programa com maiores conhecimentos sobre política é confirmada com $95 \%$ de confiança. Ser participante causa efeito de 0,623 sobre o conhecimento político se comparado aos não participantes, mantendo as demais variáveis do modelo constantes. Vale destacar que, ao longo do tempo, tanto o grupo de tratamento quanto o de controle ganham conhecimento sobre política.

O tempo 2 causou influência de 0,192 sobre o conhecimento dos entrevistados em relação ao tempo 1 mantendo as demais variáveis constantes. Isto pode ser explicado devido à efervescência do 
SAMPAIO, T.; SIQUEIRA, M. Impacto da educação cívica sobre o conhecimento político...

momento eleitoral de 2008, ano em que foi realizada a pesquisa, e a faixa etária dos entrevistados correspondente à primeira experiência do voto.

No entanto, ao separar somente o efeito do Parlamento Jovem sobre os participantes ao longo do tempo, medido pela variável "Interação Participante x Tempo" - que foi construída pela multiplicação do tempo e do grupo -, percebe-se que o projeto tem efeito nulo, por não ser significativo no modelo, porém, tendendo a ser negativo. Este achado corrobora o indicado pela análise descritiva anterior. Isto significa que o grupo de controle desenvolve o seu conhecimento com mais sucesso do que os participantes do PJ. Entretanto, esta afirmação deve ser analisada cuidadosamente, pois é preciso perceber quem perde e quem ganha com o projeto.

Os ganhos de conhecimento político são assimétricos entre os participantes: no grupo que admite relação afetiva com a política, ao atribuir alta importância a ela em sua vida, o impacto é de 0,209 sobre o conhecimento. Este coeficiente significativo ao nível de confiança de 99\% mostra que o PJ tem efeito positivo entre aqueles que têm relação afetuosa com a política. Assim, por um lado, os mais interessados são aqueles com maiores ganhos, pois eles são mais expostos às informações políticas e percebem a influência direta da política em seus cotidianos. Por outro lado, os participantes desencantados, que possuem relação afetiva mais tênue com a política, tendem a permanecer no mesmo estágio de conhecimento de quando ingressaram no projeto ou a se confundirem ainda mais sobre o universo político. Sendo assim, o projeto não consegue estimular um ambiente de equiparação de níveis de conhecimento, ao contrário, estas diferenças acentuam-se ao longo do tempo.

Os coeficientes de regressão da Tabela 4 ainda trazem uma curiosidade sobre as variáveis que conduzem o sucesso dos ganhos de conhecimento e confirmam as hipóteses apresentada para este modelo. As variáveis que compõem a dimensão individual são todas estatisticamente significativas, o que mostra: ser homem tem impacto de 1,130 no conhecimento em relação às mulheres, ser do terceiro ano agrega mais conhecimento em detrimento dos demais alunos do Ensino Médio (1,724), e aqueles que possuem propensão a debater destacam-se sobre os demais participantes, com influência de 0,446 sobre a ampliação do conhecimento.

A variável sobre os atributos da família com maior poder explicativo sobre a aquisição de conhecimento é a escolaridade dos pais: aumentando um ano de escolaridade dos pais, e mantendo as outras variáveis constantes, eleva-se 1,144 a probabilidade de o filho ter conhecimento sobre política. Esta afirmação é feita levando em consideração o nível de confiança de 99\%. A escolaridade dos pais mostrou-se, neste modelo, o preditor com maior impacto sobre o conhecimento político, isto ao se observar que, entre as variáveis é a que apresenta o maior coeficiente padronizado $(0,331)^{18}$.

Já em relação aos ambientes socializadores, ser de escola privada impacta o conhecimento em 0,499 ao se comparar com a escola pública, isto para um nível de confiança de 90\%. Por sua vez, já ter participado de outros ambientes de socialização antes do Parlamento Jovem aumenta em 0,697 0 conhecimento, tendo como referência debutantes em programas de educação cívica. Isto a um nível de confiança de $95 \%$.

18 O beta padronizado se encontra em uma escala de desvios-padrão, o que torna sua interpretação não intuitiva - aumentando um grau na escolaridade dos pais, aumenta-se 0,331 desvios-padrões sobre o conhecimento. No entanto, ele apresenta a possibilidade de comparação dos resultados do impacto dos coeficientes sobre a variável dependente. 
Tanto a variável "ser pertencente à elite" quanto a variável "estudar em escolas com grêmios" não foram significativas estatisticamente ao se considerar todas as variáveis do modelo ceteris paribus. Os pressupostos estatísticos obrigatórios para apresentação dos coeficientes da regressão foram observados.

Os dados apresentados, tantos os originados da estatística descritiva (medidas de centro e variância) quanto da inferencial, mostraram a direção do processo do aprendizado político proporcionado pelo PJ aos participantes. Aqueles que possuíam dimensão afetiva com a política mais consolidada foram os que obtiveram os melhores resultados esperados, quando comparados aos "desencantados". Isto pelo fato de o PJ não conseguir com êxito criar um ambiente homogêneo entre os participantes para que o conhecimento fosse disseminado de maneira igualitária.

\section{Considerações Finais}

A promoção da educação cívica vem sendo tratada como essencial para a consolidação e difusão dos princípios democráticos. Assim, programas como o Parlamento Jovem preenchem esse espaço na formação política de jovens estimulando a capacitação para disseminação de normas e valores. No entanto, esse processo enfrenta obstáculos que levam a resultados opostos ao esperado.

O desencanto pela política é o óbice primário a ser transposto. O PJ volta-se a mobilizar e motivar sobre questões que, para a maioria dos jovens, são alheias ao cotidiano e de difícil compreensão. Com isso, a estratégia utilizada pelo programa atinge apenas uma pequena parcela possuidora de grau moderado de sofisticação política, ou seja, aqueles jovens com baixo interesse e conhecimento pela política têm pouca motivação para participar de programas de educação cívica.

Dessa forma, como foi demonstrado aqui, o PJ concentra indivíduos cuja visão sobre o mundo político é distante da demonstrada pela maioria dos jovens não participantes. Os efeitos do programa são, mais uma vez, mitigados, pois, ao agregar apenas aqueles com sofisticação política à tarefa de remodelar normas e valores que tais indivíduos recebem de instituições como, por exemplo, a família, o programa provoca reações como desestímulo a continuar participando ou, em alguns casos, conduz os participantes a se manterem na defensiva.

Aqueles mais sofisticados, possuidores de esquemas poderosos sobre o ambiente político logo partem para o contra-ataque apresentando justificativas adequadas às suas crenças e dificultando o processo de consolidação e difusão de princípios democráticos. Por outro lado, quando isso não acontece, o que se percebe é a ampliação do desencanto. Com isso, há a construção da política como espaço onde predominam interesses pessoais e coadunam objetivos escusos.

Desse modo, o desempenho dos participantes restringe-se a condicionantes moldadas pela cognição e pelo afeto. Consequentemente, o PJ é limitado na consecução daquilo a que se propõe. 0 conhecimento adquirido pelos participantes é distante do ideal, ou seja, o que a pesquisa apresenta é que não há homogeneização dos princípios democráticos com o desencanto, muitas vezes criado pelo PJ, levando a níveis díspares de aprendizado entre os envolvidos. 
SAMPAIO, T.; SIQUEIRA, M. Impacto da educação cívica sobre o conhecimento político...

\section{Referências Bibliográficas}

Almond, G.; Verba, S. The civic culture: political attitudes and democracy in five nations. Princeton: Princeton University Press, 1989.

CARothers, T. "Democracy assistance: the question of strategy". Democratization, vol. 4, n 3, p. 109-132, 1997.

CONOVER, P.; Feldman, S. "How people organize the political world: a schematic model". American Journal of Political Science, vol. $28, n^{\circ} 1$, p. 95-126, 1984.

Cosson, R. Escolas do legislativo, escolas de democracia. Brasília: Câmara dos Deputados, 2008.

Delli CarPINI, M.; COOK, L.; JacoBs, L. "Public deliberation, discursive participation, and citizen engagement: A review of the empirical literature". Annual Review of Political Science, vol. 7, p. 315-344, 2004.

FINKEL, S. "Can democracy be taught?" Journal of Democracy, vol. 14, n4, p. 137-151, 2003.

FINKEL, S.; ERNST, H. "Civic education in post-apartheid South Africa: alternative paths to the development of political knowledge and democratic values". Political Psychology, vol. 26, n 3, p. 333-364, 2005.

Finkel, S.; SabatinI, C.; Bevis, G. "Civic education, civil society, and political mistrust in a developing democracy: the case of the Dominican Republic". World Development, vol. 28, p. 1851-1874, 2000.

FINKEL, S.; SMITH, A. "Civic education, political discussion and the social transmission of democratic knowledge and values in a new democracy: the 2002 Kenya". American Journal of Political Science, vol. 55, n² 2, p.417.435, 2011.

FUKS, M. "Efeitos diretos, indiretos e tardios: trajetórias da transmissão intergeracional da participação política". Lua Nova, vol. 83 , p. $145 \cdot 178,2010$

"Atitudes, cognição e participação política: padrões de influência dos ambientes de socialização sobre o perfil político dos jovens". Trabalho apresentado no IV Congresso Latino Americano de Opinião Pública da WAPOR. Belo Horizonte, 2011.

FuKS, M.; FIALHO, F. "Mudança institucional e atitudes políticas: a imagem pública da Assembleia Legislativa de Minas Gerais (1993-2006)". Opinião Pública, vol. 15, n¹, p. 82-106, 2009.

JenKINS, K.; ANDOlinA, M.; KeETER, S.; ZUKIN, C. "Searching for the meaning of youth civic engagement: notes from the field". Applied Developmental Science, vol. 6, n 4, p. 189-195, 2002

JENKINS, K.; ZUKIN, C.; ANDOLINA, M. Three core measures of community-based civic engagement: evidence from the youth civic engagement indicators project. In: Child Trends Conference on Indicators of Positive Development. Washington, DC; 1990.

JenNINGS, K.; NiEMI, R. "The transmission of political values from parent to child". The American Political Science Review, vol. $62, \mathrm{n}^{\circ} 1$, p.169.184, 1968.

KUKLINSKI, J.; LUSKIN, R. "Where the schema? Going beyond the "s" word in political psychology". The American Political Science Review, vol. 85, n4, p.1341-1356, 1991

KUKLINSKI, J.; QUIRK, P. Reconsidering the rational public: cognition, heuristics, and mass opinion. In: LUPIA, A.; McCUBBINS, M. D.; POPKIN, S. L. (eds.). Elements of reason: cognition, choice, and the bounds of rationality. New York: Cambridge University Press, p. 153.82, 2000.

LODGE, M.; TABER, C. "The automaticity of affect for political leaders, groups, and issues: an experimental test of the hot cognition hypothesis". Political Psychology, vol. 26, n³, p.455-482, 2005.

LuPIA, A.; McCubBins, M. The democratic dilemma: Can citizens learn what they need to know? New York: Cambridge University Press, 1998.

The institutional foundations of political competence: how citizens learn what they need to know. In: LUPIA, A.; McCuBbins, M. D.; Popkin, S. L. (eds.). Elements of reason: cognition, choice, and the bounds of rationality. New York: Cambridge University Press, p. 47-66, 2000.

MANGUE, D. "(In)formação, um caminho para a participação política? Um estudo de caso sobre o programa de educação para a cidadania da ALMG". Belo Horizonte. p. 214. Dissertação de Mestrado em Ciência da Informação - Escola de Ciência da Informação, Universidade Federal de Minas Gerais, 2008. 
Putnam, R. Comunidade e democracia: a experiência da Itália moderna. Rio de Janeiro: FGV, 1996.

SeARS, D.; VAlEntino, N. "Politics matters: political events as catalysts for preadult socialization". The American Political Science Review, vol.91, n¹, p. 45.65, 1997.

SLOMZYNSKI, K.; SHABAD, G. "Can support for democracy and the market be learned in school? A natural experiment in post. communist Poland". Political Psychology, vol. 19, n 4, 1998.

TEDIN, K. "The influence of parents on the political attitudes of adolescents". The American Political Science Review, vol. 68, $n^{\circ}$. 4, p.1579-1592, 1974.

Verba, S.; BURNS, N.; SChLOZMAN, K. "Knowing and caring about politics: gender and political engagement". The Journal of Politics, vol. 59, n4, p. 1051-1072, 1997.

\section{Anexo 1 \\ Construção dos Índices de Conhecimento Político}

Índice de Conhecimento sobre Democracia (ICD)

O Índice de Conhecimento sobre a Democracia foi criado a partir da pergunta que pedia aos participantes apontarem a presença ou ausência na democracia de elementos como: o direito ao voto, o poder do Presidente em fechar o Congresso, aprovação direta das leis pelos cidadãos, entre outras questões. Recodificaram-se estas respostas como "Acertou" = 1 e "Errou" = 0. Somaram-se os erros e acertos de cada um. Assim, o menor escore que os respondentes podiam alcançar era 0 no caso de erro em todas as respostas e 8 a maior pontuação possível nos casos em que houvesse acerto em todas as questões.

A categorização desta variável obedeceu ao seguinte critério: aqueles que não acertaram nenhuma resposta ou acertaram apenas uma foram categorizados como conhecimento "Muito Baixo"; aqueles que responderam corretamente a duas ou três questões são os de conhecimento "Baixo"; os que acertaram quatro possuem um nível razoavelmente "Normal"; quem obteve um escore de cinco e seis acertos foi considerado como de conhecimento "Alto"; por fim, os respondentes que tiveram sete e oito acertos obtiveram um nível de conhecimento "Muito alto".

Índice de Conhecimento sobre Instituições do Poder Legislativo (ICPL)

Este índice foi originado a partir da variável que media o conhecimento dos entrevistados acerca das instituições que compõem o Poder Legislativo. As respostas foram recodificadas como "Acertou" = 1 e "Errou" = 0. Novamente, somaram-se os erros e acertos de cada um, o menor escore que os respondentes podiam alcançar era 0 , caso errassem todas as respostas, e a maior pontuação alcançada era de 6 no acerto de todas as respostas.

A mesma escala de 5 pontos foi utilizada para classificar o conhecimento dos respondentes sobre o poder Legislativo: "Muito Baixo", "Baixo", "Normal”, "Alto", "Muito Alto". Os categorizados como "Muito Baixo" não acertaram nenhuma questão; conhecimento "Baixo" estavam entre 1 e 2 acertos; aqueles que foram considerados como "Normal" responderam corretamente 4 ou 5 questões; os que acertaram as 6 opções foram os de conhecimento "Muito Alto". 
SAMPAIO, T.; SIQUEIRA, M. Impacto da educação cívica sobre o conhecimento político...

Índice de Conhecimento do Espectro Ideológico Partidário (ICP)

Este índice foi formado obedecendo ao mesmo padrão dos outros dois índices. Baseou-se na questão que pedia aos respondentes que classificassem os partidos políticos entre direita e esquerda. A variável foi binarizada considerando "0" os erros e "1" os acertos. A soma da pontuação de acertos de cada respondente variou entre 0 e 6, que, respectivamente, referem-se àqueles que não acertaram nenhuma e aos que acertaram todas. Novamente, categorizaram-se os acertos como: 0, conhecimento "Muito Baixo"; 1 e 2, conhecimento "Baixo"; 3,"Normal"; 4 e 5, "Alto"; e 6 "Muito Alto".

Índice Geral de Conhecimento

Índice formado a partir da soma dos índices anteriores (ICD, ICPL, ECP). No entanto, para a sua construção, optou-se por fazê-lo em uma escala de três pontos: "Pouco Conhecimento", "Conhecimento Razoável" e "Muito Conhecimento". A manipulação dos dados para se chegar a esta escala aconteceu da seguinte forma: para cada um dos índices (ICD, ICPL, ECP), recodificou-se sua escala original agregando o "Baixo" e "Muito Baixo" como "Pouco Conhecimento" (= 0). "Alto" e "Muito Alto" foram considerados como "Muito Conhecimento" (=2). Por sua vez, os de conhecimento "Normal" passaram a ser classificados como "Conhecimento Razoável” (=1). Esta estratégia foi necessária por observarmos que havia grupos com pouquíssimos casos, o que poderia complicar a análise estatística quanto à significância dos dados. Ao agrupá-los, estes ficaram mais robustos para as análises, apresentando no mínimo 30 casos para cada uma das novas categorias.

Após a recodificação dos índices, estes foram somados. A escala do Índice Geral variou de 0 a 6. Esta foi recategorizada da seguinte forma, os escores 0 e 1 foram chamados de "Pouco Conhecimento", pontuações entre 2 e 4 como "Conhecimento Razoável” e por fim, 5 e 6 pontos como "Muito Conhecimento".

\section{Anexo 2}

\section{A construção dos Índices de Importância Política}

Índice de Exposição à Informação Política

Este índice mede os hábitos dos entrevistados na aquisição de informação sobre a política e se baseia na questão: com que frequência os entrevistados se informavam sobre política através de jornais, conversas, TV, internet, entre outros. O procedimento para criação do índice foi pensado para três pontos: "Pouco informado", "Informado", "Muito Informado". Os que se informavam diariamente foram recodificados como 2 ("Muito informado"); os entrevistados que buscavam informações algumas vezes por semana ou algumas vezes por mês foram classificados como 1 ("Informado"); e os que se informavam raramente ou nunca receberam o código 0 ("Pouco Informado").

Após esta recodificação, somaram-se os escores dos respondentes. Esta soma variou de 0 a 14. Os entrevistados que se informavam diariamente em todos os meios possíveis obtiveram o máximo de 14, e aqueles que raramente ou nunca se informavam ficaram com o mínimo de 0. Esta soma foi recategorizada da seguinte forma: os respondentes com pontuação de 0 a 4 foram considerados "Pouco Informados" (=0); se esta foi de 5 a 9 foram classificado como "Informados" (= 1); e os que obtiveram pontuação acima de 10 foram classificados como "Muito informados" (=2). 
OPINIÃO PÚBLICA, Campinas, vol. 19, n², novembro, 2013, p. 380-402

Índice de Interesse por Política

O Índice de Interesse por Política visa captar o grau de interesse dos entrevistados em relação à política ele foi concebido a partir de uma única questão, que pede ao entrevistado que responda: "Em relação à política você é muito interessado, interessado, pouco interessado ou nada interessado?".

Esta variável foi recodificada como: "Pouco Interessado" (=0), aqueles que declararam possuir pouco ou nenhum interesse por política. Os "Interessados" passaram a receber o código "1" e os "Muito interessados" foram recodificados como "2". Como é um índice formado por apenas uma pergunta, não foi preciso fazer somatórios. Assim, a variação do índice de interesse por política varia de 0 a 2 (pouco informado, informado e muito informado).

Índice de Atribuição de Influência da Política

Este índice mede o quanto os entrevistados consideram como influentes os procedimentos políticos no dia-a-dia. A questão que deu origem a este índice perguntava: "Você diria que o que acontece na política tem muita influência, alguma influência, pouca influência ou nenhuma influência na sua vida"?

Como no índice anterior, o mesmo procedimento foi seguido: agregou-se "nenhuma influência" à "pouca influência", e isto foi recodificado como 0. Os que disseram que a política tinha "alguma influência" passou a receber o código 1. Aqueles que declararam "muita influência", receberam o código 2. A recodificação desta maneira foi necessária para construir categorias padrões entre os índices. Quanto mais perto de 0 , menos importância a variável medida possui na vida do respondente, quanto mais perto de 2, mais influência.

Índice Geral de Importância Política

O Índice Geral de Importância Política foi elaborado a partir dos três índices anteriores (Índice de Exposição à Informação política, Índice de Interesse por Política e Índice de Atribuição de Influência da Política). Tal índice surgiu para possibilitar a captação dos perfis de indivíduos capazes de explicar seus comportamentos frente à aquisição de conhecimento.

A variação do somatório possível é de 0 a 6. Recodificaram-se os escores 0 e 1 como "pouco importante" (=1), ou seja, a política possui pouca importância para sua vida; as pontuações entre 2 a 4 foram classificadas como "importante" $(=1)$; e os escores entre 4 a 6 remetem aos que consideram a política como "muito importante" (=2).

Thiago Sampaio - thiagosampaio@ufmg.br

Marina Siqueira·marinapuccs@gmail.com

Submetido à publicação em março de 2012. Versão final aprovada em novembro de 2012. 